\title{
Experimental and Numerical Investigation of Adhesively Bonded Curved Lap Joints under Three-Point Bending
}

\author{
Şerif ÇiTiL \\ Adiyaman University, Department of Mechanical Eng., Adlyaman, 02040, Turkey, E-mail: scitil@adiyaman.edu.tr \\ crossref http://dx.doi.org/10.5755/j01.mech.24.6.22472
}

\section{Introduction}

Adhesive joints are commonly used in mechanical structures and in many industrial areas such as electronics, automobile, maritime, aviation, and space. Traditional joint methods such as welding, riveting, and bolt are preferred for reasons such as easy assembling and low cost. However, it is widely known that very high stress intensity may occur at joint points and that damages at lower stress levels than estimated may occur when these joints are used with traditional materials [1]. For this reason, adhesive joints have been an excellent alternative to traditional joint methods such as welding, riveting, and bolt [2]. In particular, it is advantageous to use adhesive joints for structures that are desired to be light [3]. The ability to easily bond different types of materials with the adhesive and the formation of uniform stress distribution in the joint area are other advantages of adhesive joints [4].

It is possible to find many joint configurations in the industry. Especially single lap joints are the most preferred joint model due to ease of use. However, stress distributions are quite complicated although the joint type is simple [5]. The fact that the adhesive joint exhibits a great change in its strength depending on the type of the joint is thought to be unsuitable as a mechanical bonding key. The effective application of adhesive joints in the future is important to estimate the strength of the adhesive joint under different types of external loads [6]. For this reason, in the design of adhesive joints, it is very important to know the stress distribution in the interface of the joint due to various external loads.

Many studies on how to follow a stress-strain behavior using different joint models such as under tensile load, step [7-8], angle [9-12], overlap [13-18], butt joint [1923], embedded covers [24], intermediate element [25] were carried out in the literature. Furthermore, studies on the strength of the adhesive were also carried out under different types of external loads for various types of adhesive joints. For this purpose, various adhesive joint models were subjected to loads such as three-point and four-point bending, and anti-symmetric, and investigations were conducted on what kind of tensile behavior the joint would exhibit in the interface [26-29].

The developing manufacturing technology has made it possible to create more complex geometric configurations in an easy way. The easiest and most practical of the adhesive joint configurations is undoubtedly the overlap joint. However, today's technologies are now providing opportunities to create even the most difficult configurations in an easy way. For this reason, it is of great importance to investigate adhesively bonded special joint

models according to load cases. Furthermore, for the analysis of the joint model, the finite element method is the numerical technique improved to deal with the studies such as complex structures in which conventional methods often fail, and nonlinear material properties [30]. Therefore, it is now quite easy to numerically model complex or specific configurations in adhesive joints.

In adhesive lap joints, the strength of the joint exhibits quite different behaviors depending on the joint model and the application state of the load. Different joint models are developed using today's technologies for the adhesive to carry more loads in adhesive joints. In this study, a new joint model, a curved lap joint was formed. The curved lap joint formed was subjected to three-point bending moment by increasing its radius of curvature. What kind of strength behavior the adhesively bonded curved lap joint under threepoint bending moment would exhibit in its interface depending on the increase in radius was numerically and experimentally investigated.

\section{Material and method}

\subsection{Materials}

Aluminum alloy AA2024-T3 sheets with non-linear behavior as joint elements, and two-component acrylic structural adhesive (DP410) produced by the $3 \mathrm{M}$ company as bonding elements were used in the damage analysis of this study. The Raghava criterion (Eq. 1), which is known as the generalized Drucker-Prager yield criterion, was used in the non-linear finite element analysis of the joints. The equation given in Equation (1) can be written in a different form as it is shown below [31-34]. Here, $q$ represents the von-Mises equivalent stress, $\sigma_{m}$ represents the average stress or hydrostatic stress, and $e$ represents the damage index. Here, $\lambda, \sigma_{t}$ (compressive), $\sigma_{c}$ (tensile) and $\tau_{y}$ are the hydrostatic stress sensitivity parameter associated with shearyield stresses. The equation given in Equation (2) is represented in ANSYS (version 15) package program as follows [35]. Here, if $\alpha$ and $b$ pressure sensitivity parameter associated with hydrostatic stress are written together and rearranged with equations (2) and (4), the following equation is derived for $\alpha$. Furthermore, one of the parameters that need to be defined for the exponent Drucker-Prager model, $E_{a}$, $v_{e}, \alpha$, is $\psi$, the dilatation angle.

The dilatation angle is calculated as follows.

$$
\begin{aligned}
& \left(\sigma_{1}-\sigma_{2}\right)^{2}+\left(\sigma_{2}-\sigma_{3}\right)^{2}+\left(\sigma_{3}-\sigma_{1}\right)^{2}+ \\
& +2\left(\sigma_{c}-\sigma_{t}\right)\left(\sigma_{1}+\sigma_{2}+\sigma_{3}\right)=2 \sigma_{c} \cdot \sigma_{t} \cdot \mathrm{e} . \\
& \frac{q^{2}}{\lambda \sigma_{t}^{2}}+\frac{3 \sigma_{t}(\lambda-1) \sigma_{m}}{\lambda \sigma_{t}^{2}}=e \quad \begin{cases}e \geq 1 & \text { failure } \\
e<1 & \text { no failure }\end{cases}
\end{aligned}
$$




$$
\begin{aligned}
& q^{2}+\alpha \sigma_{m}=\sigma_{t}^{b} . \\
& \alpha=3 \sigma_{t}(\lambda-1) . \\
& \tan \psi=\frac{3\left(1-2 v_{p}\right)}{2\left(1+2 v_{p}\right)} .
\end{aligned}
$$

Bulk samples were prepared to achieve the parameters $(\lambda, \alpha, \psi, \sigma$ and $\tau)$ needed for the analysis of the adhesive material in the finite element analysis of joint models by the Drucker-Prager model [36-38]. The necessary parameters were obtained by tensing four bulk samples prepared in the tensile testing device at a tensile speed of $1 \mathrm{~mm} / \mathrm{min}$ at room temperature (Table 1, Figs. 1 and 2). Moreover, the mechanical properties of the bonded material are given in Fig. 3 and Table 2.

Table 1

Material parameters for the exponent Drucker-Prager model (DP410)

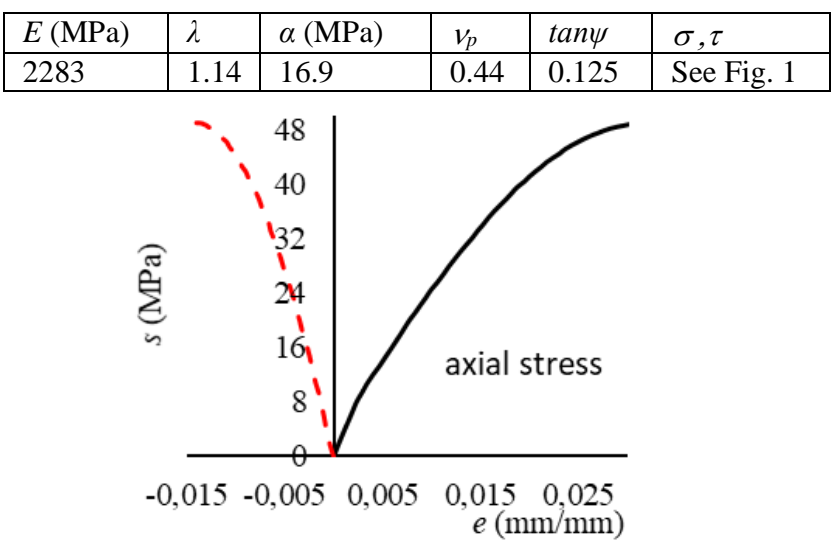

Fig. 1 Lateral stress-strain and longitudinal stress-strain behaviors of adhesive (DP410) obtained from uniaxial loading conditions by using video extensometer

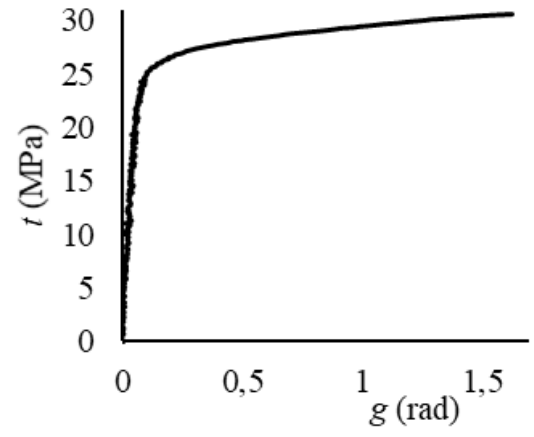

Fig. 2 Shear stress-shear strain behavior of DP410

Table 2

Physical and Mechanical Properties of Adherend (AA 2024-T3)

\begin{tabular}{|c|c|}
\hline \multirow{2}{*}{ Properties } & Materials \\
\cline { 2 - 2 } & $A A 2024-T 3$ \\
\hline$E, \mathrm{MPa}$ & 71875 \\
\hline$v$ & 0.33 \\
\hline$\sigma_{t}, \mathrm{MPa}$ & 481.9 \\
\hline$\varepsilon_{t}$ & 0.1587 \\
\hline
\end{tabular}

$E$ is Young's Modulus; $v$ is Poisson's ratio; $\sigma_{t}$ is Ultimate tensile strength; $\varepsilon_{t}$ is Ultimate tensile strain.

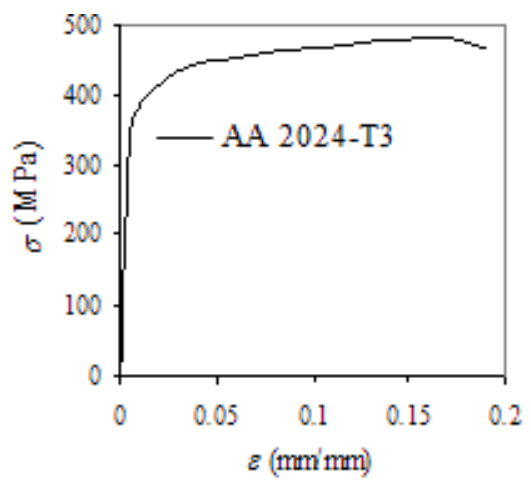

Fig. 3 tensile stress-strain curve for AA2024-T3

\subsection{Experimental modeling}

The experimental samples were produced with a thickness of $h=6.5 \mathrm{~mm}$ and a width of $w=25 \mathrm{~mm}$ and an overlap length of $l=25 \mathrm{~mm}$ (Fig. 1). The curved surfaces with radii of $r=100,300,500 \mathrm{~mm}$ were formed by increasing the radius of the curved lap joint by $200 \mathrm{~mm}$. The samples were produced in a way to have four separate samples with radii of $r_{1}(99.9,299.9,499.9)$ and $r_{2}(100.1,300.1,500.1)$ depending on the radius of curvature $(r)$ to obtain the adhesive thickness $(t=0.2 \mathrm{~mm})$ between the adherents to be bonded (Fig. 4). The preliminary preparation was performed by cleaning the surfaces of experimental samples before bonding with the adhesive. Then, adhesively bonded samples were put into a mold and obtained by keeping waiting at $120{ }^{\circ} \mathrm{C}$ for 60 minutes (Fig. 5).

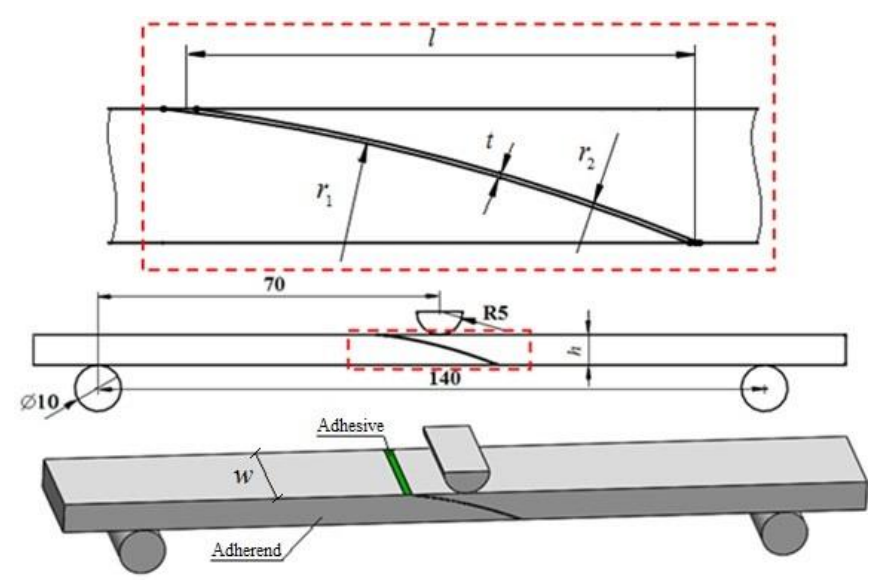

Fig. 4 Curved lap joint

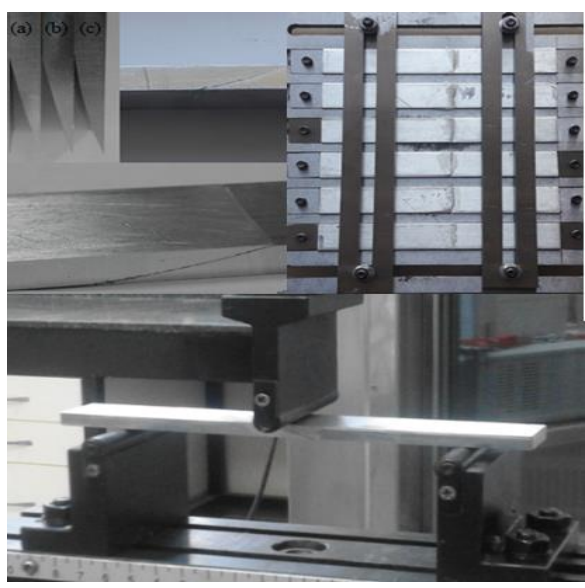

Fig. 5 Experimental samples (a) $r=100 \mathrm{~mm}$ (b) $r=300 \mathrm{~mm}$ (c) $r=500 \mathrm{~mm}$ 
After the experimental samples were produced, they were subjected to three-point bending moment in the universal tensile testing device at a compression speed of 1 $\mathrm{mm} / \mathrm{min}$ at a room temperature of $24{ }^{\circ} \mathrm{C}$ and in a humid environment of $35 \%$ (Fig. 5).

\subsection{Numerical modeling}

In this study, adhesively bonded joint types were made using the non-linear finite element model ANSYS (version 15) package program [39]. The non-linear material properties of the adhesive and aluminum alloy used in numerical models under three-point bending moment are presented in Tables 1 and 2, and Fig. 1. The geometric properties, load and boundary conditions of the joint models created were modeled three-dimensionally in a way that they would be the same as those used in the experimental analyses (Fig. 6). In the finite element analysis, the models were obtained by being divided by Solid 186 element with 20 node points. The critical joint region was divided into smaller elements to obtain an accurate estimate of the stress distributions between the adhesive and the plate (Fig. 6).

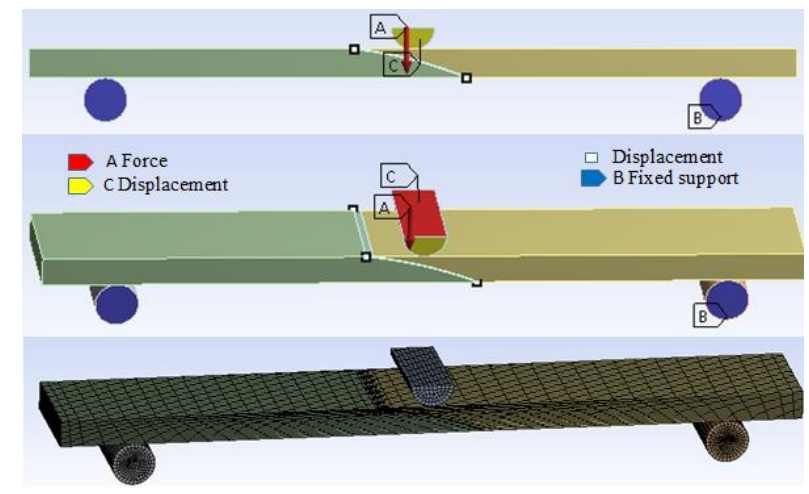

Fig. 6 Three-dimensional modeling of the curved lap joints

\section{Results and discussion}

\subsection{Experimental and numerical results}

The experimental samples that were produced in a way to have four separate samples with radii of curvature of $r=100,300,500 \mathrm{~mm}$, respectively, for adhesively bonded curved lap joints with a thickness of $h=6.5 \mathrm{~mm}$, a width of $w=25 \mathrm{~mm}$ and an overlap length of $l=25 \mathrm{~mm}$ were subjected to three-point bending moment, and damage load results were obtained. The experimental damage load results obtained, and the numerically obtained damage load results are presented graphically in Figure 5. In the experimental and numerical analyses, the distance between the supports was taken as $140 \mathrm{~mm}$ for each sample. Furthermore, the moving jaw on which the load was applied was applied at the midpoint of the sample and at a distance of $70 \mathrm{~mm}$ to each support (Figs. 4 and 6).

When the joint models created are subjected to three-point bending moment, there is a triaxial stress state on the adhesive layer. For this reason, equivalent stresses $\left(\sigma_{e q}\right)$ were calculated according to the Drucker-Prager yield criterion given in equation (4). It has been assumed that damage occurs when equivalent stress reaches the tensile strength $\left(\sigma_{t}\right)$ of the adhesive at any point of the adhesive layer. In Fig. 7, the load-deformation relation of each joint type under three-point bending moment is given numerically and experimentally. When the experimental and numerical results are examined, it is observed that load deformation relations are compatible. It was observed that the curved lap joint with a radius of curvature of $r=500 \mathrm{~mm}$ carried the highest damage load and the curved lap joint with a radius of curvature of $r=100 \mathrm{~mm}$ carried the lowest damage load. It was observed that the damage loads carried increased as the radius of curvature increased.

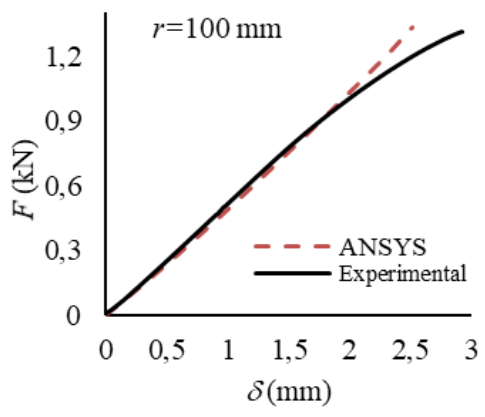

a

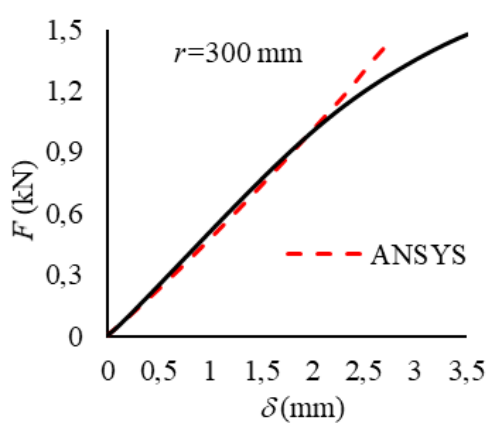

b

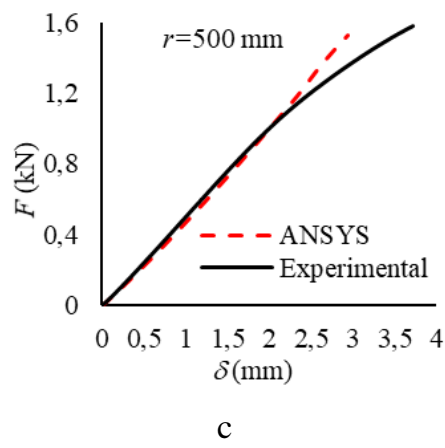

Fig. 7 Experimental and numerical damage load results a) $r=100 \mathrm{~mm}$, b) $r=300 \mathrm{~mm}$, c) $r=500 \mathrm{~mm}$

\subsection{Stress distribution results}

A compression load was applied in the -y-direction along the surface EFGH to obtain the stress distributions of curved lap joints under three-point bending moment (Fig. 8). The stress distributions of the joint models were obtained three-dimensionally along the surface ABCD. The curved lap joints were obtained separately for the adherend thickness of $h=6.5 \mathrm{~mm}$, the overlap length of $l=25 \mathrm{~mm}$ and radii of $r=100,300,500$. The results obtained are presented in Figs.7, 8, 9, 10, 11 and 12. For the comparison of stress distributions, $1.3 \mathrm{kN}$ load was applied to the surfaces of EFGH so that the same load would be applied to each joint sample. The applied load is the lowest damage load obtained in numerical analyses. 


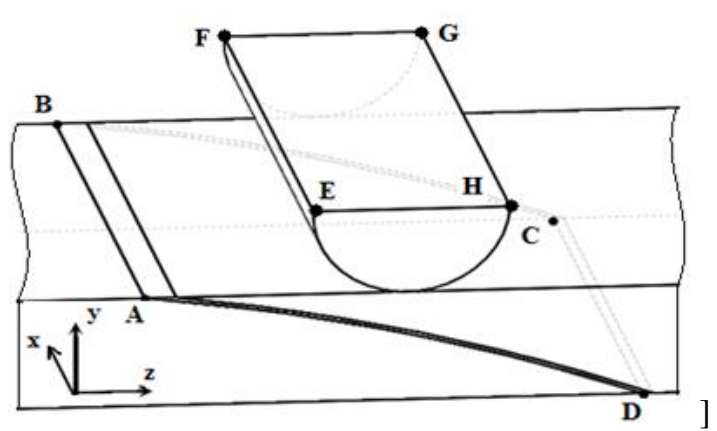

Fig. 8 The surface on which the three-dimensional stress distributions are taken (ABCD)

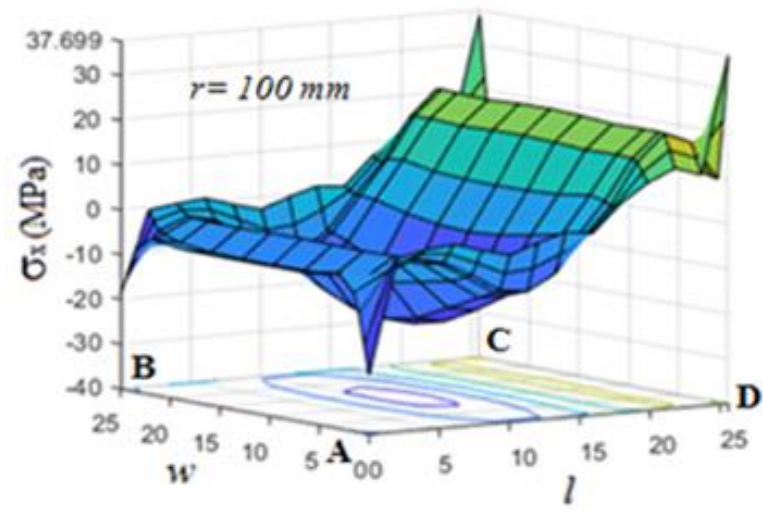

a

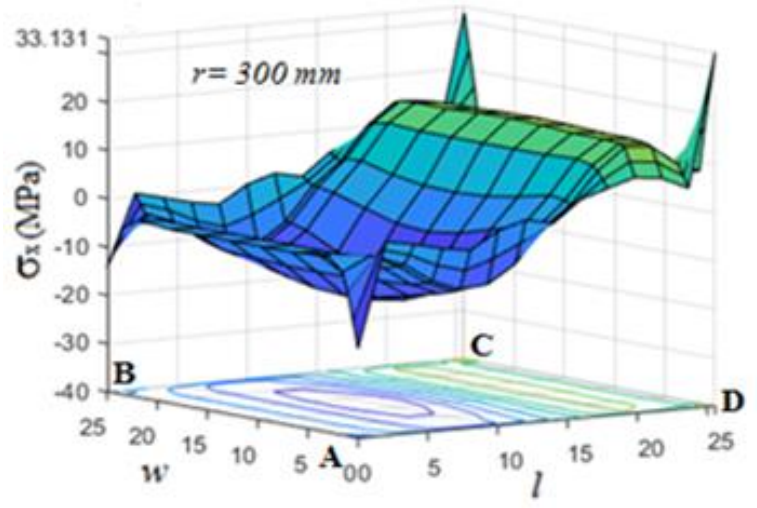

b

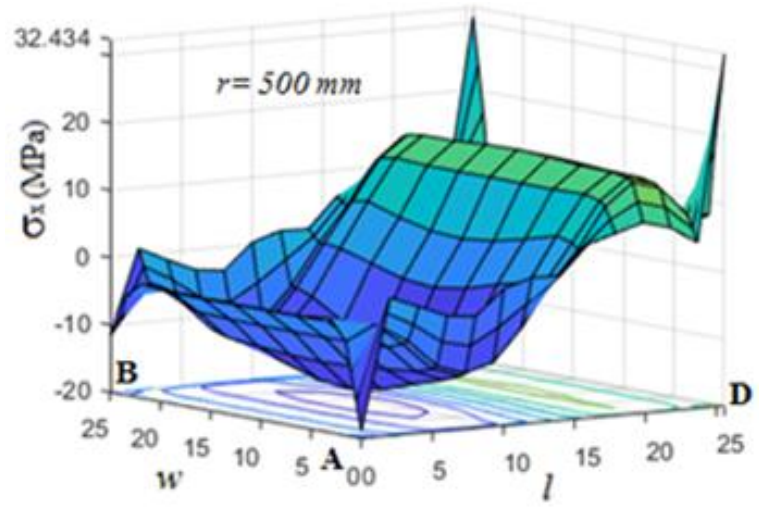

c

Fig. 9 Peel stress $\left(\sigma_{x}\right)$ along the surface ABCD (a) for $r=100 \mathrm{~mm}$ (b) for $r=300 \mathrm{~mm}$ (c) for $r=500 \mathrm{~mm}$

Normal stress distributions along the surface $\operatorname{ABCD}\left(\sigma_{x}, \sigma_{y}, \sigma_{z}\right)$ are presented three-dimensionally in figures 9,10 , and 11 . When stress distributions are examined,

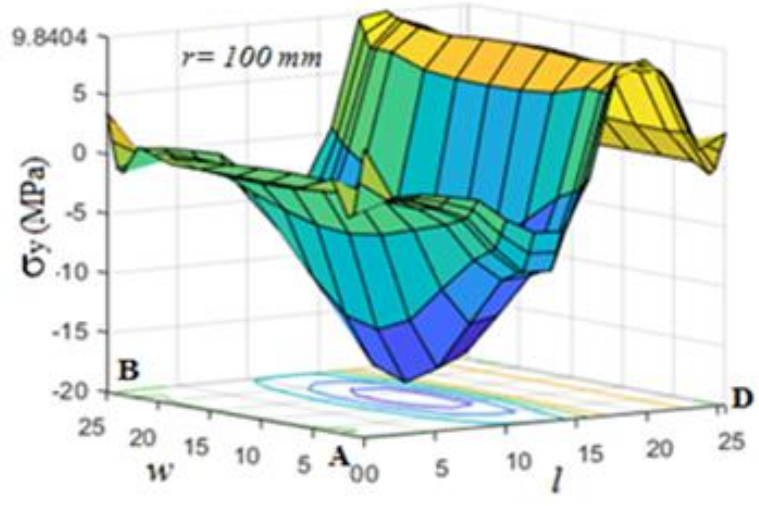

a

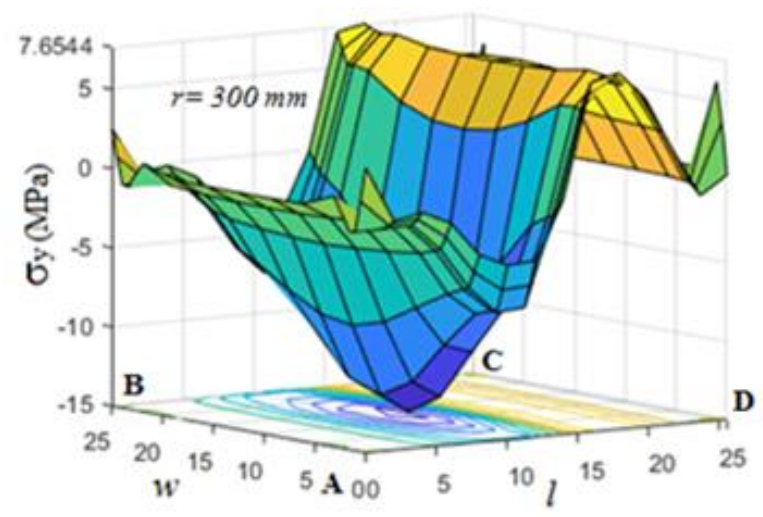

b

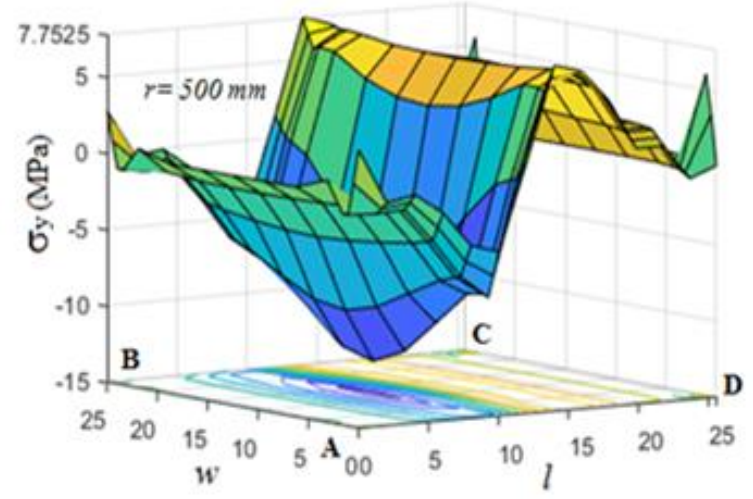

$\mathrm{c}$

Fig. 10 Peel stress $\left(\sigma_{y}\right)$ along the surface ABCD (a) for $r=100 \mathrm{~mm}$ (b) for $r=300 \mathrm{~mm}$ (c) for $r=500 \mathrm{~mm}$

it is observed that the highest normal stresses occurred in the curved lap joint with a radius of curvature of $r=100 \mathrm{~mm}$. When $\sigma_{x}$ normal stress distributions are examined, it took a negative value in the region of line $\mathrm{AB}$ and became positive as going towards the line $\mathrm{CD}$ by changing the sign in the middle of the overlap length. This indicates that the adhesive was forced to compress from the region of line $\mathrm{AB}$ to the very middle region and to tense after the middle region. The left side was subjected to compression, and the right side was subjected to tensile load since the adhesive in the adhesive joint was located in the upper region of the neutral axis (the horizontal at a distance of $h / 2$ ) on the left side of the point where the load was applied, and it was located in the sub-region of the neutral axis on the right side of the point where the load was applied. It was observed that the stresses were close to zero in the very middle. It is observed that normal $\left(\sigma_{x}, \sigma_{y}, \sigma_{z}\right)$ stresses are maximum at the points 
A, B, C and D. However, when stress distributions are examined, it is observed that the stresses increase as going towards the intermediate regions (range of 5-10 $\mathrm{mm}$ and range of $15-20 \mathrm{~mm}$ ) along the overlap length. In particular, the endpoints and intermediate regions are critical regions where damage begins. It is observed that normal stresses were higher in the curved lap joint with a radius of curvature of $r=100 \mathrm{~mm}$ compared to other lap joints in the endpoints and intermediate regions. It was observed that normal stress $\left(\sigma_{x}, \sigma_{y}, \sigma_{z}\right)$ values decreased as the radius of curvature increased. Here, the flatness of the surface on which the adhesive was applied increases as the radius of curvature increases. The fact that the surface is flattened indicates that it is subjected to less peel stress.

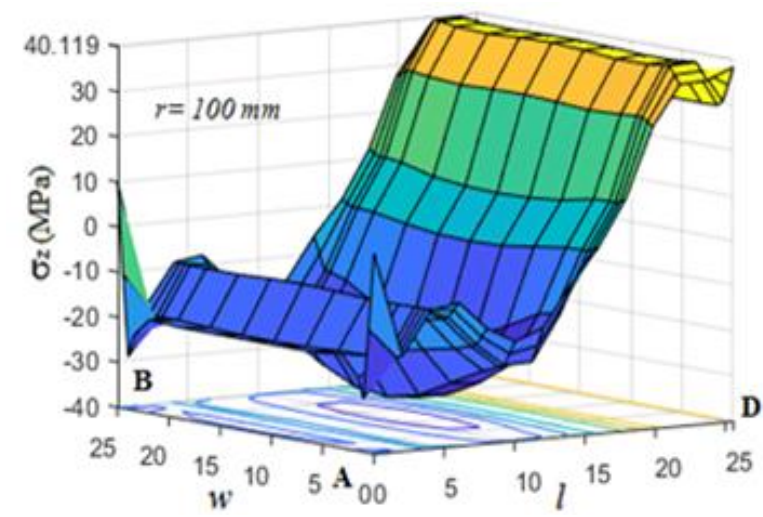

a

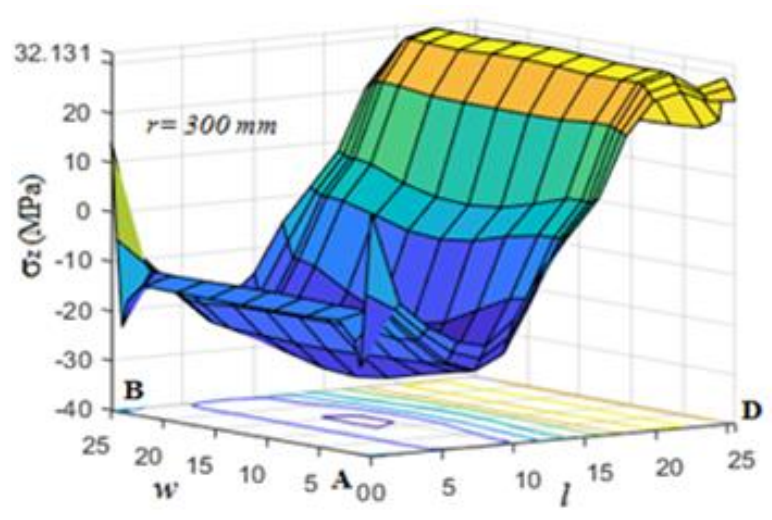

b

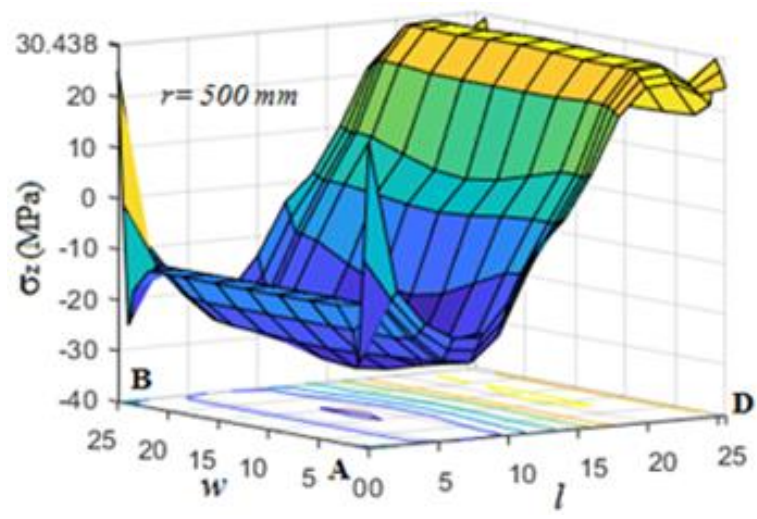

C

Fig. 11 Peel stress $\left(\sigma_{z}\right)$ along the surface $\operatorname{ABCD}$ (a) for $r=100 \mathrm{~mm}$ (b) for $r=300 \mathrm{~mm}$ (c) for $r=500 \mathrm{~mm}$

$\tau_{x y}, \tau_{x z}$ and $\tau_{y z}$ stress distributions of the curved joint model are presented in Figs. 12, 13 and 14. It is observed that $\tau_{x y}$ and $\tau_{x z}$ shear stresses were subjected to compression and tensile-induced stresses along the width $(w)$ (lines AB and $\mathrm{CD})$. It is observed that $\tau_{\mathrm{xy}}$ and $\tau_{\mathrm{xz}}$ shear stresses had maximum values along the lines $\mathrm{AD}$ and $\mathrm{BC}$. It is observed that shear stresses approached zero in the intermediate region. When curved lap joints are examined along the width $(w)$, it is observed that $\tau_{x y}$ and $\tau_{x z}$ shear stresses decreased as the radius of curvature increased. Especially the endpoints and intermediate regions (ranges of 5-10 mm and 15-20 $\mathrm{mm})$ are critical regions for $\tau_{x y}$ and $\tau_{x z}$ shear stresses.

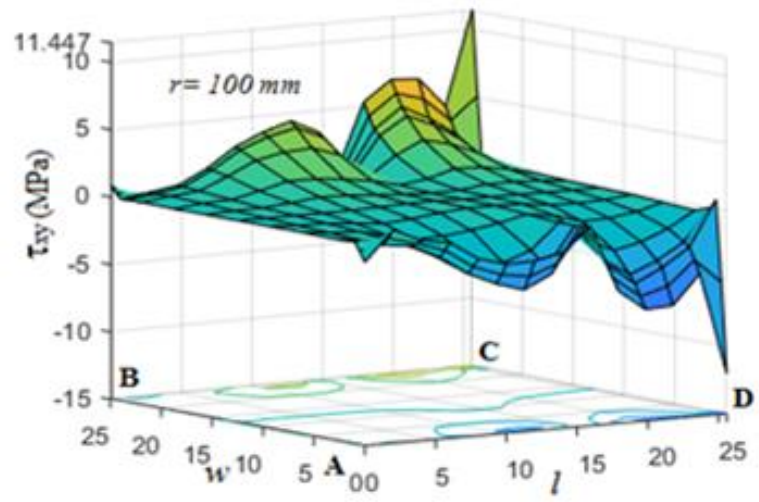

a

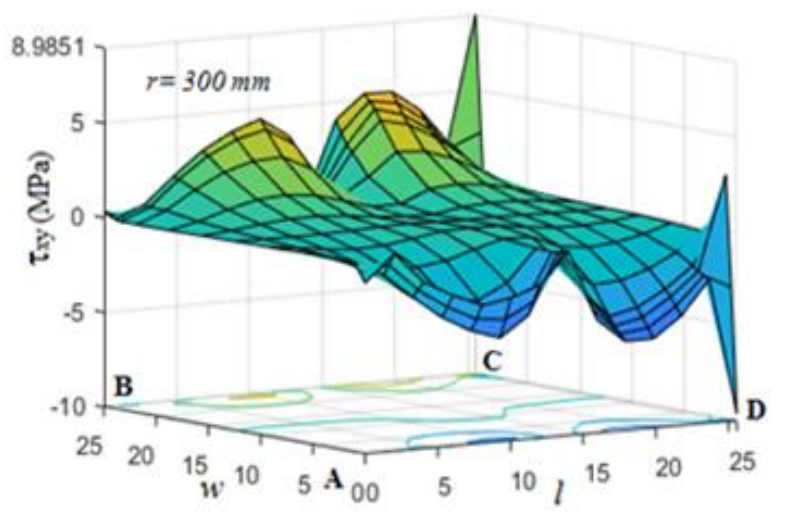

b

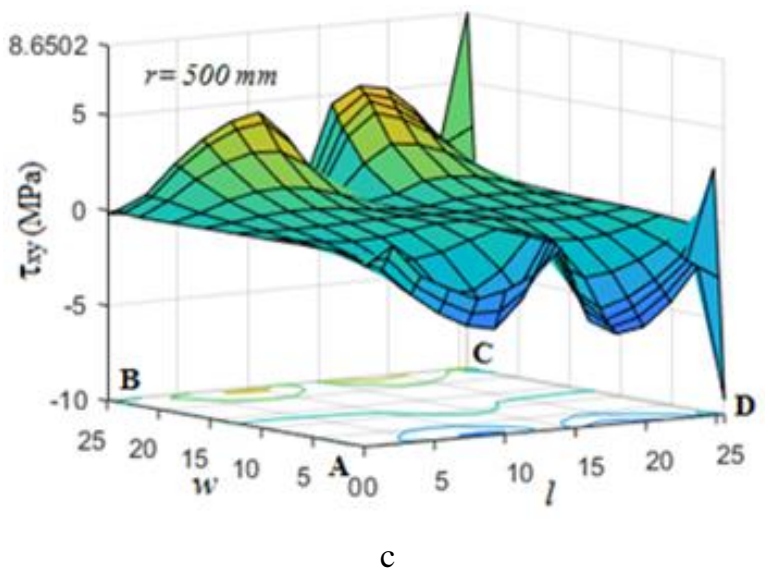

Fig. 12 Shear stress $\left(\tau_{x y}\right)$ along the surface ABCD (a) for $r=100 \mathrm{~mm}$ (b) for $r=300 \mathrm{~mm}$ (c) for $r=500 \mathrm{~mm}$

In Fig. 14, when $\tau_{y z}$ stress distributions are examined, it is observed that $\tau_{y z}$ shear stresses had almost the same values depending on the increase in radius. It is observed that only $\tau_{y z}$ shear stress was subjected to compression and tensile stresses not along the width $(w)$ but along 
the overlap length $(l)$. The curved lap joints are forced to shear on the $y z$ plane rather than $x y$, and $x z$ planes. $\tau_{y z}$ shear stresses peaked compared to shear stresses $\left(\tau_{x y}\right.$, and $\left.\tau_{x z}\right)$ on the other planes. The endpoints and intermediate regions are also critical regions for $\tau_{y z}$ shear stresses.

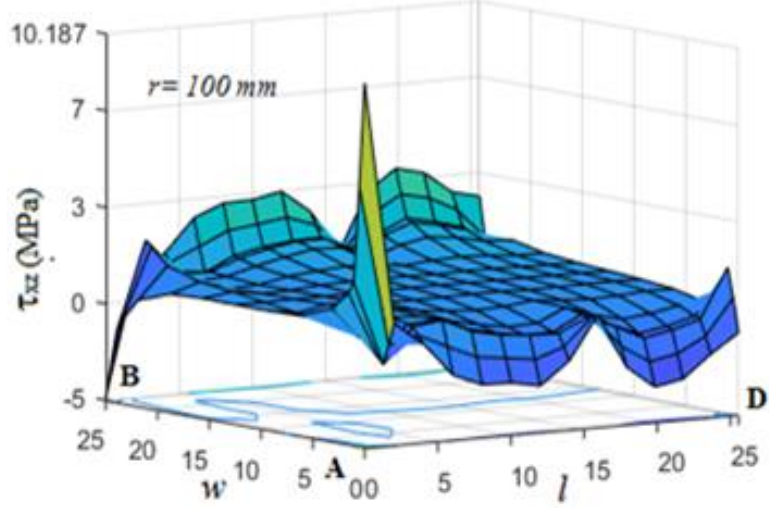

a

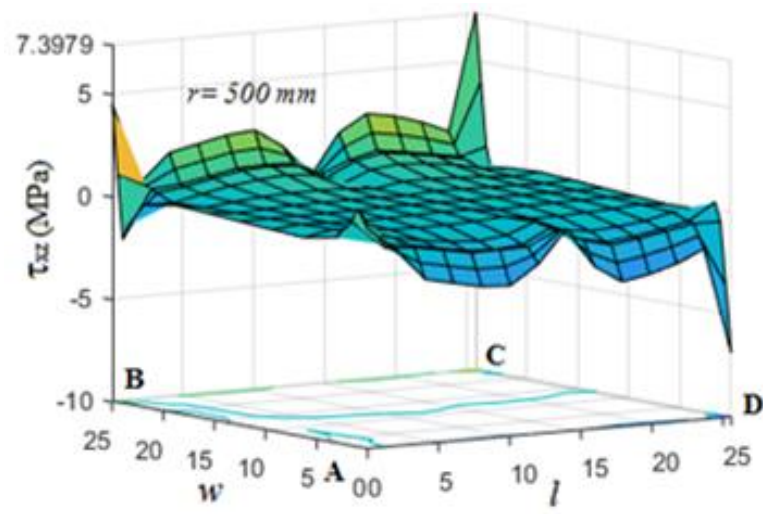

b

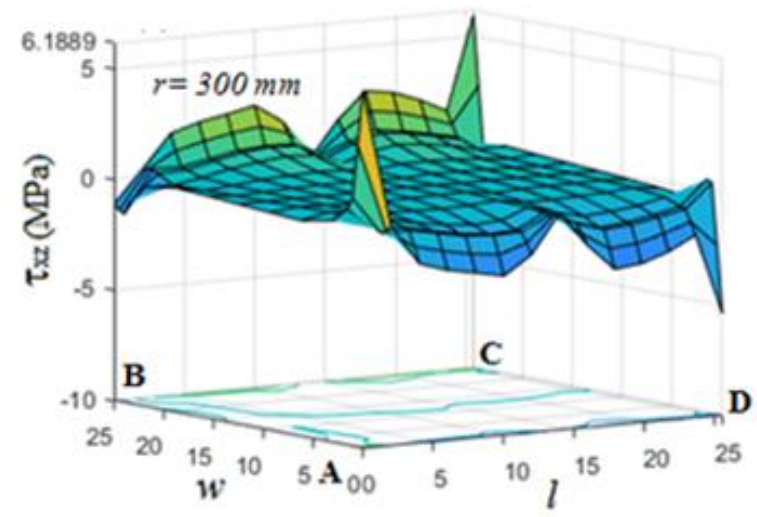

c

Fig. 13 Shear stress $\left(\tau_{x z}\right)$ along the surface ABCD (a) for $r=100 \mathrm{~mm}$ (b) for $r=300 \mathrm{~mm}$ (c) for $r=500 \mathrm{~mm}$

The damage indexes of the curved lap joints under three-point bending moment along the overlap length (along the line $\mathrm{AD}$ ) on the adhesive layer were compared in Figure 15. As it was previously mentioned in the material and method section, the damage index $(e)$ is a parameter used to estimate the strength of the joint. The damage index of the adhesive must be $e<1$. If the damage index is $e \geq 1$, this indicates that damage has occurred in the adhesive. As it can be understood in Fig. 15, the highest damage index occurred in the curved lap joint with a radius of curvature of $r=100$ $\mathrm{mm}$. It was observed that the damage index decreased as the radius of curvature increased. In particular, it is observed that damage started especially in the region close to the point $\mathrm{D}$ along the line $\mathrm{AD}$.'
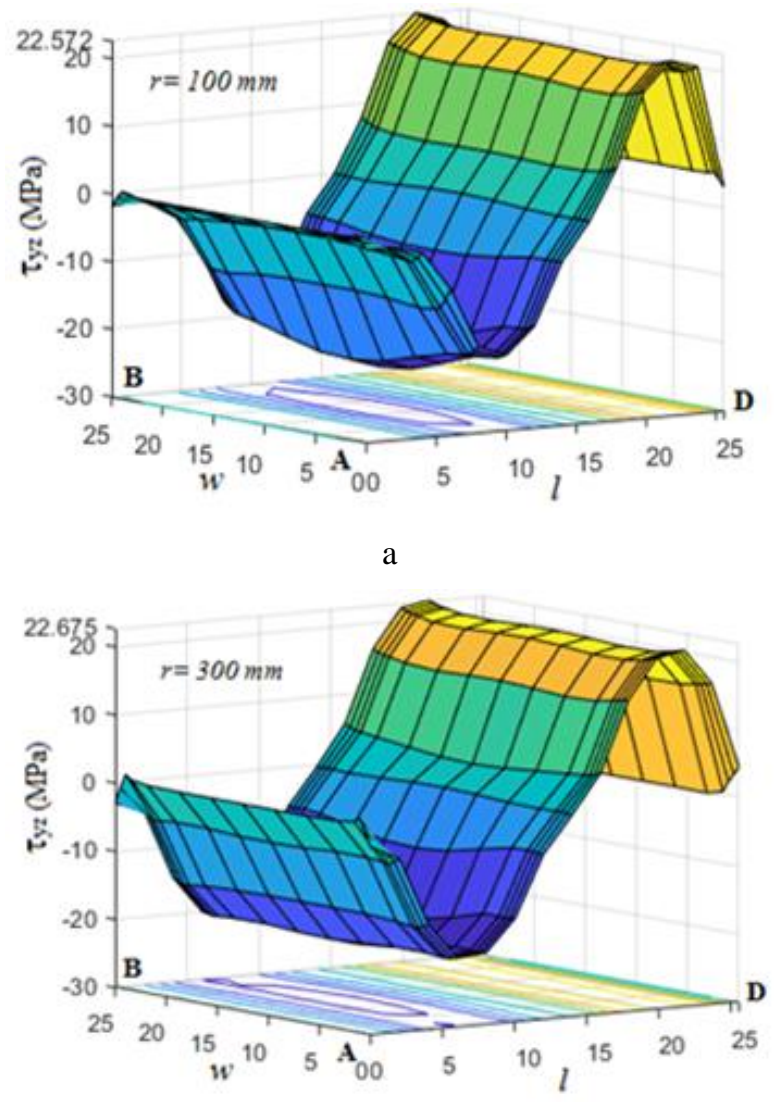

b

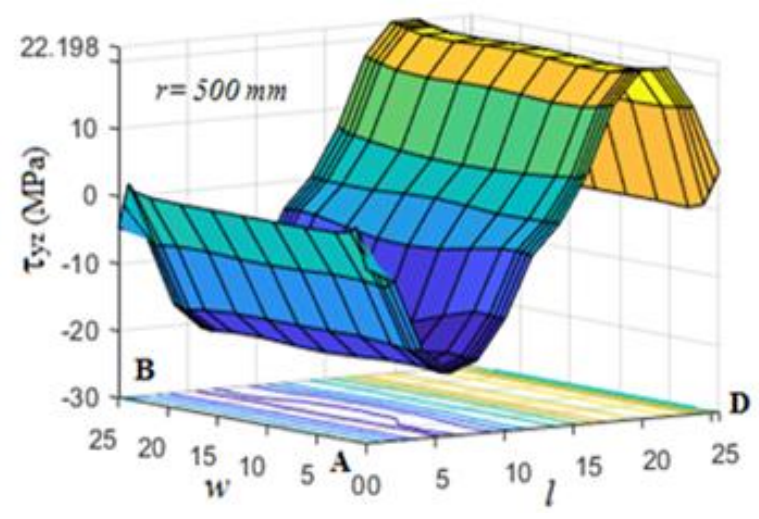

$\mathrm{C}$

Fig. 14 Shear stress $\left(\tau_{y z}\right)$ along the surface ABCD (a) for $r=100 \mathrm{~mm}$ (b) for $r=300 \mathrm{~mm}$ (c) for $r=500 \mathrm{~mm}$ 

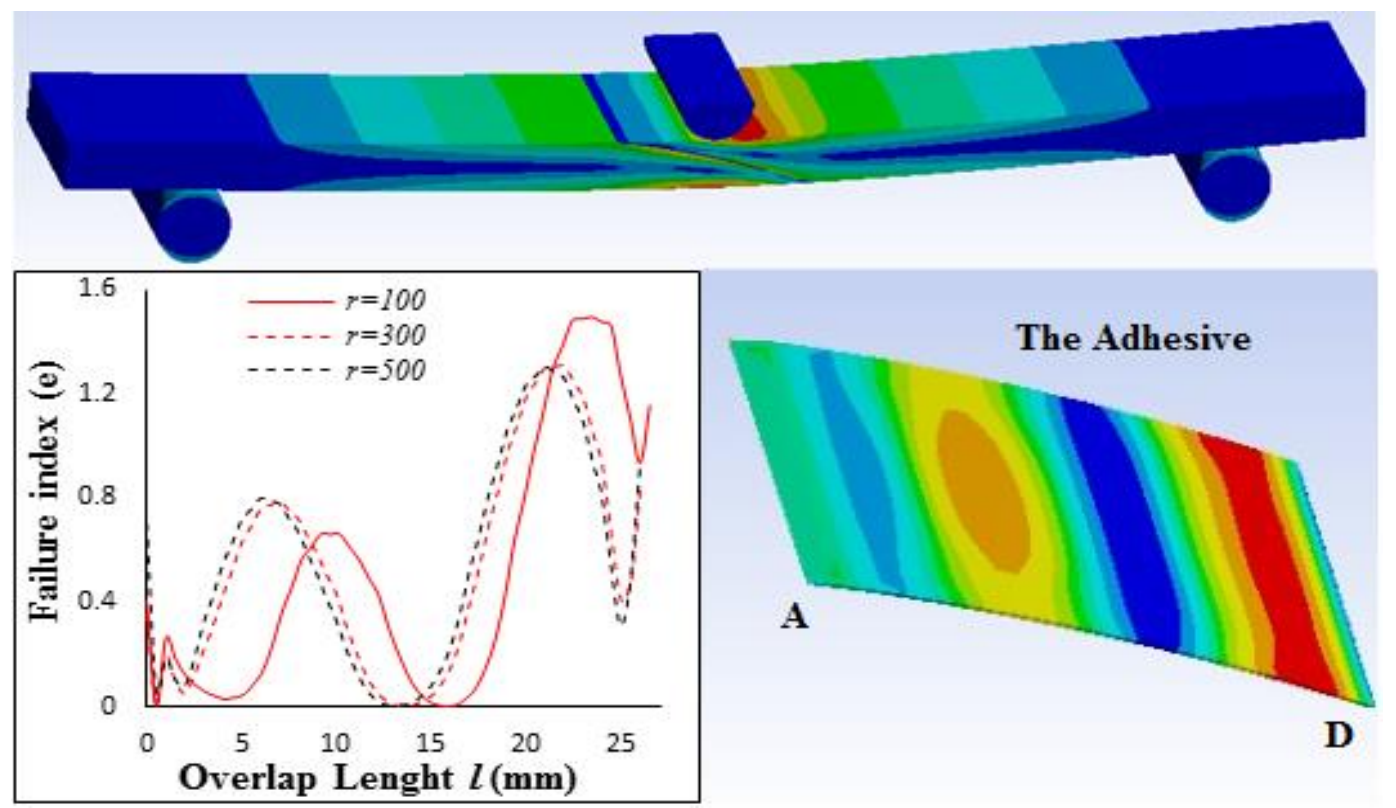

Fig. 15 Failure indexes (e) along the line AD (a) for $r=100 \mathrm{~mm}$ (b) for $r=300 \mathrm{~mm}$ (c) for $r=500 \mathrm{~mm}$

\section{Conclusions}

In this study, curved surface lap joints were subjected to three-point bending moment by increasing the radius of curvature. The damage index and stress distributions of the curved lap joints under three-point bending moment were performed by a three-dimensional non-linear finite element analysis. The stress distributions were obtained threedimensionally in the non-linear finite element analysis. Verification tests were performed to verify the non-linear finite element analysis. The results obtained are presented below.

1. Experimental and numerical results were observed to be compatible.

2. According to normal stresses, it was observed that lap joints were subjected to less peel stress as the radius of curvature increased. It was observed that normal stresses $\left(\sigma_{x}, \sigma_{y}, \sigma_{z}\right)$ along the overlap length were maximum especially in the endpoints and intermediate regions (ranges of 5-10 $\mathrm{mm}$ and 15-20 $\mathrm{mm}$ ). The adhesive was located above the neutral axis (the horizontal at a distance of $h / 2$ ) on the left side of the line where the load was applied and under the neutral axis on the right side of the line where the load was applied. Therefore, stresses exhibited compression and tensile-character behaviors.

3. According to shear stresses, the curved lap joints $\left(\tau_{x y}, \tau_{x z}\right)$ are subjected to $\tau_{y z}$ shear stress rather than shear stresses and force the adhesive joint to damage. $\tau_{y z}$ shear stresses had maximum values compared to shear stresses ( $\tau_{x y}$, and $\tau_{x z}$ ) on the other planes and forced the adhesive joint to damage. While endpoints are of critical importance for $\tau_{x y}, \tau_{x z}$ shear stresses, it was observed that intermediate regions are of critical importance for $\tau_{y z}$ shear stresses.

4. According to the damage index, it was observed that the curved surface lap joint had maximum values especially in the intermediate regions (range of 15-20 mm) along the overlap length, and the damage was observed to begin especially in these regions. It was observed that the damage index decreased as the radius of curvature increased.

\section{References}

1. İçten, BM.; Karakuzu, R. 2002. Progressive failure analysis of pin-loaded carbon-epoxy woven composite plates, Composites science and technology, 62:12591271.

2. Campilho, RDSG.; Banea MD.; Pinto, AMG.; daSi va, LFM.; deJesus AMP. 2011. Strength prediction of single-and double-lap joints by standard and extended finite element modelling, International Journal of Adhesion and Adhesives, 31: 363-372.

3. Adin, H. 2012. The investigation of the effect of angle on the failure load and strength of scarf lap joints, International Journal of mechanical sciences, 61: 24-31.

4. Sawa, T.; Ichikawa, K.; Shin, Y., Kobayashi, TA. 2010. Three-dimensional finite element stress analysis and strength prediction of stepped-lap adhesive joints of dissimilar adherends subjected to bending moments, International Journal of Adhesion and Adhesives, 30: 298-305.

5. Nakano, H.; Sekiguchi, Y.; Sawa, T. 2013. FEM stress analysis and strength prediction of scarf adhesive joints under static bending moments, International Journal of Adhesion and Adhesives, 44: 166-173.

6. Domingues, N.R.E.; Campilho, R.D.S.G.; Carbas, R.J.C.; daSilva, L.F.M. 2016. Experimental and numerical failure analysis of aluminium/composite single$\mathrm{L}$ joints, International Journal of Adhesion and Adhesives, 64: 86-96.

7. Sawa, T.; Ichikawa K.; Shin, Y.; Kobayashi, T. 2010. A three-dimensional finite element stress analysis and strength prediction of stepped-lap adhesive joints of dissimilar adherends subjected to bending moments, International Journal of Adhesion and Adhesives, 30: 298-305.

8. Ichikawa, K.; Shin, Y.; Sawa, T. 2008. A three-dimensional finite-element stress analysis and strength evaluation of stepped-lap adhesive joints subjected to static tensile loadings, International Journal of Adhesion and Adhesives, 28:464-470. 
9. Afendi, M.; Teramoto, T.; Bakri, HB. 2011. Strength prediction of epoxy adhesively bonded scarf joints of dissimilar adherends, International Journal of Adhesion and Adhesives, 31:402-411.

10. Chaudhuri, RA.; Chiu, SJ. 2009. Three-dimensional asymptotic stress field in the vicinity of an adhesively bonded scarf joint interface, Composite Structures, 89: 475-483.

11. Kimiaeifar, A.; Toft, H.; Lund, E.; Thomsen, OT.; Sorensen, JD. 2012. Reliability analysis of adhesive bonded scarf joints, Engineering Structures, 35:281287.

12. Chiu, SJ.; Chaudhuri, RA. 2011. A three-dimensional eigenfunction expansion approach for singular stress field near an adhesively-bonded scarf joint interface in a rigidly-encased plate, Engineering Fracture Mechanics, 78:2220-34.

13. Lang, TP.; Mallick, PK. 1998. Effect of spew geometry on stresses in single lap adhesive joints, International Journal of Adhesion and Adhesives, 18(3):167-177.

14. Narasimhan, S.; Pandey, PC. 2003. Three- dimensional Material and Geometrical Nonlinear Analysis of Adhesively Bonded Single Lap Joint, Defence Science Journal, 53(2):175-188.

15. Liu, J.; Sawa, T.; Toratani, H. 1999. A Two-dimensional stress analysis and strength of single-lap adhesive joints of dissimilar adherends subjected to external bending moments, The Journal of Adhesion, 69(34):263-291.

16. Sawa, T.; Liu, JM.; Nakano, K.; Tanaka, J. 2000. A two-dimensional stress analysis of single-lap adhesive joints of dissimilar adherends subjected to tensile loads, Journal of Adhesion Science Technology, 14(1):43-66.

17. Liu, J.; Sawa, T. 2001. Stress analysis and strength evaluation of single-lap adhesive joints combined with rivets under external bending moments, Journal of Adhesion Science Technology, 15(1): 43-61.

18. Higuchi, I, Sawa, T, Suga, H. 2002. Three-dimensional finite element analysis of single-lap adhesive joints under impact loads, Journal of Adhesion Science Technology, 16(12): 1585-1601.

19. Reedy, Jr. ED.; Guess, TR. 1997. Interface corner failure analysis of joint strength: effect of adherend stiffness, International Journal of Fracture, 88(4):305-314.

20. Reedy, Jr. ED.; Guess, TR. 1993. Comparison of butt tensile strength data with interface corner stress intensity factor prediction, International Journal of Solids and Structures, 30(21): 2929-2936.

21. Adams, RD.; Coppendale, J. 1979. The stress-strain behaviour of axially-loaded butt joints, The Journal of Adhesion, 10(1): 49-62.

22. Reedy, Jr.ED. 1993. Asymptotic interface corner solutions for butt tensile joints, International Journal of Solids and Structures, 30(6):767-777.

23. Ochsner, A.; Stasiek, M.; Mishuris, G.; Gracio, J. 2007. A new evaluation procedure for the butt-joint test of adhesive technology: Determination of the complete set of linear elastic constants, International Journal of Adhesion and Adhesives, 27: 703-711.

24. Çitil, Ş.; Ayaz, Y.; Temiz, Ş. 2017. Stress analysis of adhesively bonded double strap joints with or without intermediate part subjected to tensile loading, The Journal of Adhesion, 93(5): 343-356.
25. Çitil, Ş.; Temiz, Ş.; Altun, H.; Özel, A. 2011. Determination of mechanical properties of double-strap adhesive joints with an embedded patch, Journal of Adhesion Science Technology, 25(18): 2555-2567.

26. Spaggiari, A.; Dragoni, E.; Brinson, H. 2016. Measuring the shear strength of structural adhesives with bonded beams under antisymmetric bending, International Journal of Adhesion and Adhesives, 67: 112-120.

27. Dragoni, E.; Brinson, H. 2016. Modeling and optimization of the sandwich beam specimen in three-point bending for adhesive bond characterization, International Journal of Adhesion and Adhesives, 68: 380-388.

28. Liao, L.; Sawa, T.; Huang, C., 2014. Numerical analysis on load-bearing capacity and damage of double scarf adhesive joints subjected to combined loadings of tension and bending, International Journal of Adhesion and Adhesives, 53: 65-71.

29. Razavi, SMJ.; Ayatollahi, MR.; Esmaeili, E.; da Silva, LFM. 2017. Mixed-mode fracture response of metallic fiber-reinforced epoxy adhesive, European Journal of Mechanics A/Solids, 65: 349-359.

30. Zhao, X.; Adams, RD.; daSilva, LFM. 2010. A new method for the determination of bending moments in single lap joints, International Journal of Adhesion and Adhesives, 30: 63-71.

31. Charalambides, MN.; Olusanya, A. 1997. The Constitutive Models Suitable for Adhesives in some Finite Element Codes and Suggested Methods of Generating the Appropriate Materials Data, NPL CMMT(B)130, National Physical Laboratory, Teddington, UK.

32. Dean, GD.; Duncan, BC. 1995. Tensile behaviour of bulk specimens of adhesives. NPL Report DMM(B) 448, National Physical Laboratory, Teddington, Middlesex, UK.

33. Read, BE.; Dean, GD.; Ferriss, DH. 2000. An elasticplastic model for the non-linear mechanical behaviour of rubber-toughened adhesives, NPL CMMT(A) 289, National Physical Laboratory, Teddington, UK.

34. Dean, GD.; Crocker, L.; Read, B.; Wright, L. 2004. Prediction of deformation and failure of rubber-toughened adhesive joints, International Journal of Adhesion and Adhesives, 24: 295-306.

35. Drucker DC.; Prager W. 1952. Soil mechanics and plastic analysis or limit design, Quarterly of applied mathematics, 10: 157-65.

36. Plastics - determination of tensile properties. Part1: General principles. ISO527-1.

37. Plastics - determination of tensile properties. Part2: Test conditions for moulding and extrusion of plastics. ISO527-2.

38. Adhesives - methods of preparing bulk specimens. Part2: Elevated-temperature-curing one-part systems. ISO15166-2.

39. The General Purpose Finite Element Software (Swanson Analysis Systems). Inc., Houston, Texas, ANSYS (Version 15). 


\section{Ş.Çitil}

EXPERIMENTAL AND NUMERICAL INVESTIGATION OF ADHESIVELY BONDED CURVED LAP JOINTS UNDER THREE-POINT BENDING

\section{S u m m a r y}

In this study, the curved type joint model, which is an alternative to conventional joint models, was developed and subjected to three-point bending moment by increasing the radius of curvature of the joint. The radius of curvature of the curved lap joint under three-point bending moment was increased, and its effects on strength were investigated. Furthermore, a three-dimensional non-linear finite element analysis of the joint model was performed using the generalized Drucker-Prager yield criterion. Verification tests were performed to verify the numerical solutions obtained by the non-linear finite element method.

For this purpose, curved surfaces with radii of $r=100,300,500 \mathrm{~mm}$ were formed on AA 2024-T3 aluminum sheets with a thickness of $6.5 \mathrm{~mm}$, and they were bonded with DP410 acrylic structural adhesive. In accordance with the numerical and experimental results, the radius of curvature was observed to have significant effects on damage load and stress distribution in curved lap joints under three-point bending moment.

Keywords: Adhesive, curvature, finite elements, threepoint bending.

Received July 10, 2018

Accepted December 12, 2018 